\title{
Re-evaluation of Cortical and Thalamic Responses Evoked by Stimulation of the Cerebellar Fastigial Nucleus in the Cat
}

\author{
Minoru Nakamura and Yoshihiro Matsuda* \\ Department of Neurosurgery, *Department of Physiology \\ Nagasaki University School of Medicine, Nagasaki, 852 Japan
}

\begin{abstract}
In view of the discrepancies in reports about the cerebral responses induced by stimulation of the cerebellar fastigial nucleus in the cat, attempts were made to re-evaluate the effects of stimulation of the fastigial nucleus in the cerebral cortex and thalamus of cats anesthetized with pentobarbital. Stimulation of the fastigial nucleus elicited responses of low amplitude bilaterally in the medial portion of the precruciate cortex in 7 out of 25 animals studied. The responses were mainly composed of a positive wave which reversed its polarity at a depth between 250 and $500 \mu \mathrm{m}$ from the cortical surface. Presumable relay cells for the responses were detected in the ventromedial nucleus and the medial area of the ventrolateral nucleus of the thalamus. Thalamic neurones showed a tendency to repetitive spike generation with variable latencies after fastigial stimulation, while conditioning stimuli applied to the midbrain reticular formation apparently counteracted it, enhancing the probability of generation of a single spike at a shorter latency. The effect of pentobarbital anesthesia on the fastigio-thalamic transmission is discussed in relation to the inconstant appearance of cortical responses after fastigial stimulation.
\end{abstract}

Key Words: fastigial nucleus, cat, cortical evoked response, thalamic relay cells, reticular arousal stimuli.

It is well established that stimulation of the cerebellar interpositus and dentate nuclei evokes two types of responses in the cerebral cortex in the cat; one in the frontal motor cortex, and another in the parietal association cortex (SASAKI et al., 1972, 1973). The responses in these two areas definitely differ from each other with respect to their laminar profiles of potential distribution (SASAKI et al., 1972). In contrast to these unequivocal responses evoked by stimulation of the interpositus and dentate nuclei, there are discrepancies in reports as to the cortical

Received for publication November 8, 1982

* To whom reprint requests should be addressed.

中村 稔, 松田好弘 
responses to stimulation of the cerebellar fastigial nucleus of the cat (RISPALPAdel et al., 1971; RisPal-PAdel and Latreille, 1974; SASAKi et al., 1972, 1973). Since anatomical studies now indicate that ascending fibres from the fastigial nucleus should terminate in a certain part of the thalamus where they would make synaptic contacts with thalamo-cortical projection neurones (ANGAUT and Bowsher, 1970; COHEN et al., 1958; JANSEN and JANSEN, 1955; NAKANO et al., 1980; Sugimoto et al., 1981; ThомAS et al., 1956), it would be desirable to gain precise information about the distribution as well as the laminar profiles of responses, if any, evoked by stimulation of the fastigial nucleus. In the present study, we re-evaluated responses induced by stimulation of the fastigial nucleus in the cerebral cortex of the cat and made an attempt to identify the thalamic relay cells for the responses and to examine their response properties. Although it is conceivable that different observations in previous studies might be due to the difference in anesthetics used (chloralose and barbiturate), we performed experiments under barbiturate anesthesia in the hope that the data could be compared with the results of the studies made under the same anesthetic conditions concerning the projections from the cerebellar interpositus and dentate nuclei to the cerebral cortex.

\section{METHODS}

Data for the present report were obtained from 25 cats. The animals were anesthetized with sodium pentobarbital (Nembutal, $20-25 \mathrm{mg} / \mathrm{kg}$ i.v.). After tracheal intubation, the head of the animal was fixed to a stereotaxic instrument. A craniectomy was performed to expose the left cerebral hemisphere and the cerebellum. Part of the parietal cortex and the underlying fornix were sucked away to expose the dorsal surface of the thalamus. Bipolar concentric electrodes of $0.5 \mathrm{~mm}$ in outer diameter were inserted into the fastigial nucleus on both sides and also into the interpositus nucleus contralateral to the exposed hemisphere. In each experiment responses to stimulation of the cerebellar nuclei were first explored with a ball-tipped silver electrode on the exposed surface of the cerebral cortex. Stimuli were square-wave pulses of $0.1-0.2 \mathrm{msec}$ in duration and were held below $0.2 \mathrm{~mA}$ in intensity. Recordings of field potentials in the depths of the cortex were performed with a glass microelectrode filled with $2 \mathrm{M} \mathrm{NaCl}, 2-3$ $\mathrm{M} \Omega$ in resistance.

After the exploration of cortical responses to cerebellar stimulation had been completed, three pairs of concentric stimulating electrodes were placed in the precruciate cortex, medio-laterally at an interval of $3 \mathrm{~mm}$. In experiments where the mesencephalic reticular formation was stimulated, two pairs of electrodes were inserted into the midbrain at the rostro-caudal level of the red nucleus. Extra- and intracellular recordings of responses of thalamic neurones were performed with glass microelectrodes filled with $3 \mathrm{M} \mathrm{KCl}$ which showed a DC resistance of 5-20 M $\Omega$ in saline. Responses were displayed on an oscilloscope after an AC 
amplification and photographed. When recordings were successful, the microelectrode was cut at its shoulder and left in situ in the thalamus for later histological detection of the site of recordings.

During the experiment, the animal was allowed to respire spontaneously and was injected with sodium pentobarbital, if necessary. The exposed surface of the cerebral cortex was continuously perfused with warm saline, and body temperature was controlled with a heating pad. At the completion of experiment, the animal was sacrificed by an overdose of the anesthetic and the brain was fixed with $10 \%$ formalin. The placement of stimulating electrodes was examined in frozen sections stained with cresyl violet.

\section{RESULTS}

\section{Cerebral responses evoked by stimulation of the fastigial nucleus}

It was in only 7 out of 25 animals that stimuli applied to the fastigial nucleus induced a discernible response in the cerebral cortex. In Fig. 1A are presented responses obtained from one of the animals. They were recorded on the surface of the precruciate cortex at the sites indicated in the inset diagram. Though not large in amplitude, definite responses were observed in this area of the cortex, especially in its medial portion, upon stimulation of the ipsilateral as well as contralateral fastigial (medial) nucleus (Fig. 1A, Mi and Mc). Responses to stimulation of the ipsilateral fastigial nucleus (Mi) were smaller in amplitude than those generated by stimulation of the contralateral nucleus (Mc). These responses were mainly composed of a positive wave. In contrast to them, responses to stimulation of the contralateral interpositus nucleus (Fig. 1A, Ic) were more conspicuous in the lateral than in the medial part of the precruciate area, and they were composed of a positive wave followed by a negativity. Latencies of responses to fastigial stimulation were slightly longer than those to interpositus stimulation, which may be noted in Fig. 1A. Latencies of the responses to contralateral fastigial stimulation ranged from 2.7 to $5.6 \mathrm{msec}$ ( $3.8 \mathrm{msec}$ on the average), while interpositus stimulation brought about responses with a latency ranging from 1.6 to $3.4 \mathrm{msec}$ ( $2.8 \mathrm{msec}$ on the average).

It has previously been reported that cortical responses evoked by stimulation of the cerebellar interpositus and dentate nuclei are characterized by their profiles of potential distribution in the depths of the cortex (SASAKI et al., 1972). In the present study, laminar recordings were also applied to the responses induced by stimulation of the fastigial nucleus in order to study whether or not they were identical in character to the responses generated by interpositus or dentate stimulation. In Fig. 1B is presented depth profile of the responses evoked by stimulation of the contralateral fastigial nucleus. Recordings were made in the precruciate cortex (at the site " 1 " in the inset) with a microelectrode inserted as close to perpendicular as possible to the surface of the cortex. The positive wave in the superficial layers of the cortex reversed its polarity at a depth between 250 
A

$\mathrm{Mi}$

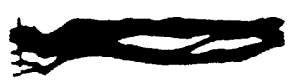

Mc

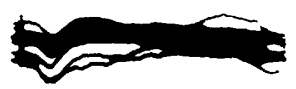

Ic

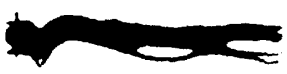

B

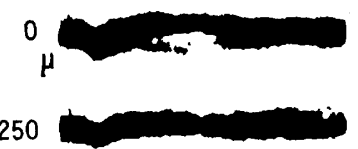

500

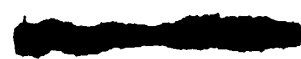

1000

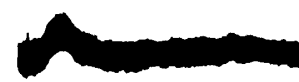

1500

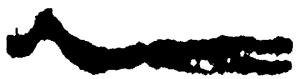

2000

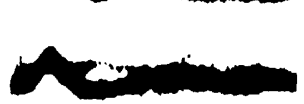

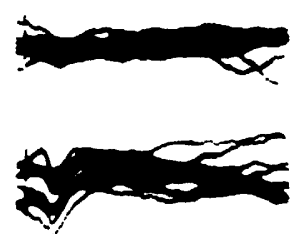
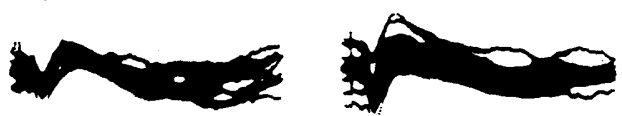

$20 \mathrm{msec}$
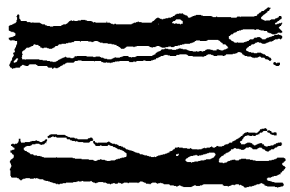

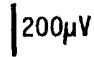

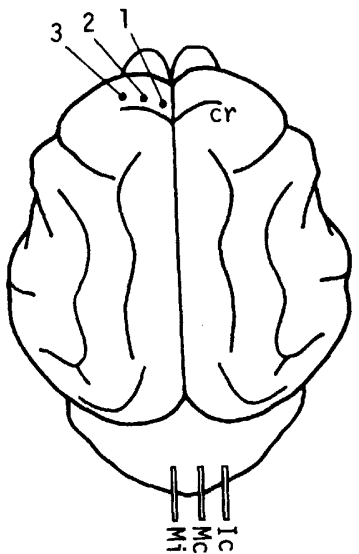

$\overline{20 m s e c}$

Fig. 1. A: cortical responses evoked by stimulation of the ipsilateral (Mi) and contralateral (Mc) fastigial (medial) nucleus and the contralateral interpositus nucleus (Ic) in an animal. Responses in each column were recorded in the precruciate cortex at the corresponding points illustrated in the inset diagram. Approximately 10 sweeps were superimposed in each frame. B: laminar recordings of responses to stimulation of the fastigial nucleus. Responses evoked by stimulation of the contralateral fastigial nucleus were recorded in the medial precruciate cortex (at the point " 1 " in the inset diagram) with a microelectrode inserted as close to perpendicular as possible to the cortical surface, the depths from the surface being indicated on the left side of each trace. In each record, 3-4 sweeps were superimposed. Upward deflexion indicates negativity.

and $500 \mu \mathrm{m}$ from the surface to become a negativity in the depths. The potential profile exactly corresponded to that of the "deep thalamo-cortical responses" (SASAKI et al., 1970) and was the same as that of the surface-positive potentials induced by interpositus or dentate stimulation (SASAKI et al., 1972). 


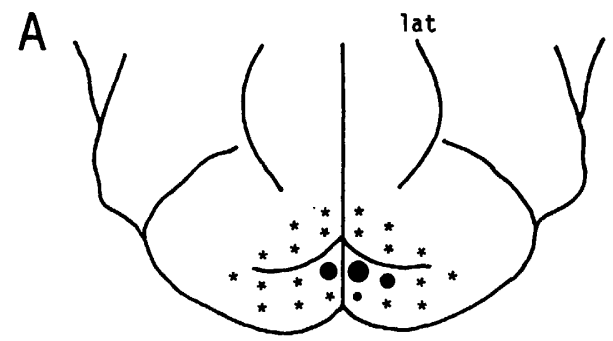

B

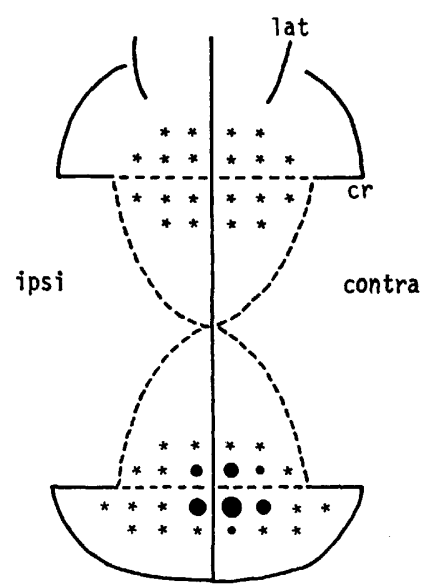

Fig. 2. Sites of generation of cortical responses to stimulation of the fastigial nucleus. A: responsive loci in the exposed area of the pericruciate cortex. Responses to stimulation of the ipsilateral and contralateral nucleus are presented with filled circles in the left and right half of the diagram, respectively. The plot is based on the data derived from 7 animals. The diameter of circles approximately indicates the relative amplitude of responses. Asterisks denote unresponsive points. B: schematic diagram summarizing cortical loci responsive to fastigial stimulation in the pericruciate area. The pericruciate cortex is illustrated with its sulcus unfolded. Responses in the hidden cortices are represented in the areas encircled by interrupted lines. lat, lateral sulcus; cr, cruciate sulcus.

With the surface electrode, responses to stimulation of the fastigial nucleus could also be recorded on the postcruciate cortex. However, microelectrode recordings in the depths of the cortex disclosed that responses were not produced in this cortical area but in the burried cortex below the cruciate sulcus (see for details SASAKI et al., 1970). Figure 2 summarizes the cortical loci responsive to stimulation of the fastigial nucleus. The precruciate area of the cortex was the only site of generation of responses to fastigial stimulation. The responses were most clearly observed in the medialmost part of the precruciate cortex just rostral to the sulcus as illustrated in Fig. $2 \mathrm{~A}$ in which the relative amplitude of the responses is approximately indicated by the diameter of filled circles. The responses were 
sometimes highly localized in this place, being lost with a slight dislocation of recording electrode. In Fig. 2B the responses in the hidden cortices are diagrammatically represented with filled circles in the areas encircled by interrupted lines. They were localized in the rostromedial portion of the ventral bank of the cruciate sulcus.

It is noteworthy that, despite elicitation of unambiguous responses in certain cats, fastigial stimulation was still ineffective in evoking cortical responses in the majority of animals studied. Histological examination indicated that the variable effects of stimulation were not ascribable to the difference in the position of stimulating electrodes in the fastigial nucleus. Thus, under barbiturate anesthesia, cortical responses to fastigial stimulation appeared to be elicited only in some favourable conditions which could not be specified in the present study. As reported previously (RISPAL-PADEL et al., 1971; RisPal-PADEL and LATREILLE, 1974), stimulation of the fastigial nucleus effectively evoked cortical responses in chloralose-anesthetized cats ( 2 experiments). Responses in these animals were detectable in a wider area of the cortex than in the barbiturate-anesthetized cats (not shown).

\section{Thalamic relay cells and their responses to stimulation of the fastigial nucleus}

The laminar profile of cortical responses to fastigial stimulation (Fig. 1B) indicated that they were conveyed by thalamo-cortical projection neurones (SASAKI et al., 1970). Attempts were made to explore thalamic relay cells for the responses and to examine the mode of their activation by fastigial stimulation. Although stimulation of the medial precruciate cortex evoked antidromic responses in neurones which distributed in a fairly wide area of the medial thalamus including the centromedial (CM), centrolateral (CL), ventrolateral (VL), and ventromedial (VM) nuclei, the relay cells, i.e., those neurones which were also activated by fastigial stimulation, were localized in the medial part of the VL nucleus as well as in the VM nucleus (filled circles in Fig. 3A). Of 56 neurones responding antidromically to cortical stimulation, 18 neurones were identified as relay cells. While the latency of antidromic responses to cortical stimulation dispersed between 0.7 and $14.4 \mathrm{msec}$ as a whole, that of the relay cells was confined within 4 msec (mean $1.8 \mathrm{msec}$ ) (Fig. 3B). Orthodromic spikes were evoked in these neurones with a latency of $1.6-4.4 \mathrm{msec}$ by stimulation of the contralateral and ipsilateral fastigial nucleus in 12 and 4 neurones respectively, 2 neurones being activated by stimulation of the nucleus on both sides.

In Fig. 4A are exemplified unitary responses of relay cells. The cells were identified as thalamo-cortical projection neurones by the antidromic nature of their responses to stimulation of the medial precruciate cortex (CX). They followed cortical stimulation at a frequency of more than $100 \mathrm{~Hz}$ without noticeable variation in latencies. However, the responses often failed to be evoked when high-frequency stimulation was applied for a prolonged period of time (Fig. $4 \mathrm{~A}_{1}$, 3rd row). Furthermore, it was frequently observed that responses to cortical 


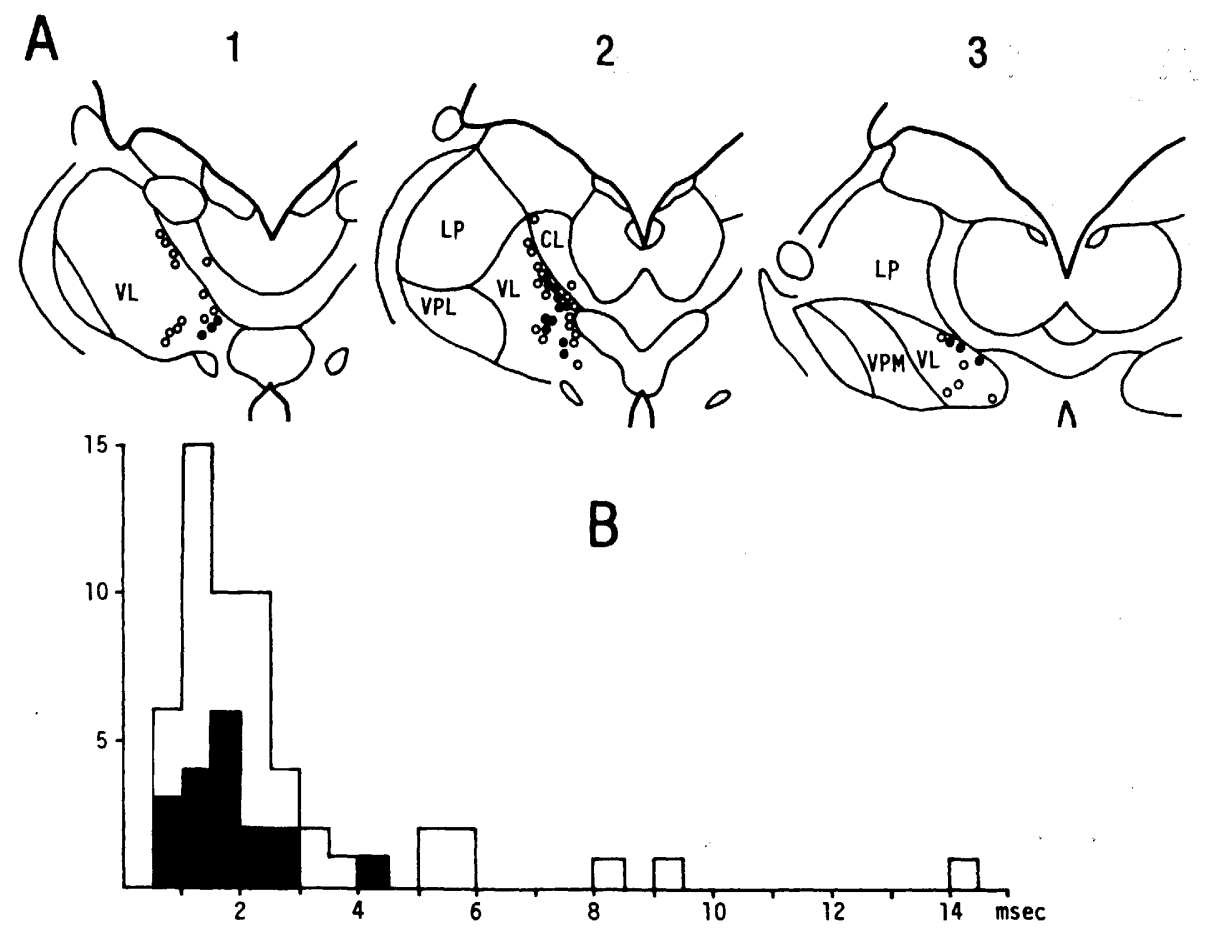

Fig. 3. A: localization of thalamic neurones projecting to the medial precruciate cortex. Filled circles indicate the sites of recordings from relay cells which responded to stimulation of the fastigial nucleus. VL, ventrolateral nucleus; CL, centrolateral nucleus; LP, posterolateral nucleus; VPL and VPM, posterolateral and posteromedial ventral nucleus. B: latency distribution of antidromic responses of neurones plotted in A. The ordinate and abscissa denote the number of cells and the spike latency, respectively. Black columns indicate responses of relay cells responding to fastigial stimulation.

stimulation took the form of a positive partial spike, indicating the failure of antidromic spike invasion of cell soma (Fig. $4 \mathrm{~A}_{2}, 3 \mathrm{rd}$ row). Stimulation of the cerebral cortex was ineffective in eliciting the responses when preceded by orthodromic spikes at appropriate intervals owing to collision extinction (PAINTAL, 1959), which also evidenced that these responses were antidromic in nature (Fig. 4A, 4th row). Thalamic neurones showed a tendency to repetitive spike generation in response to stimulation of the fastigial nucleus (Fig. 4A, upper two rows). Of 36 neurones responding orthodromically to fastigial stimulation, 17 neurones (7 relay and 10 unidentified cells) exhibited repetitive spikes in response to a single shock. Although fastigial stimulation at threshold intensities was usually effective in producing repetitive responses in most of these neurones, stimulation at suprathreshold intensities was necessary in some neurones (Fig. $4 \mathrm{~A}_{2}$, 2nd row). It was noted that latencies of responses composed of repetitive spikes varied from response to 
A
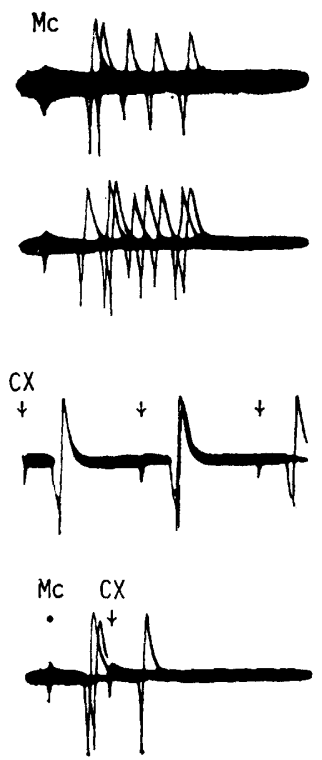

2
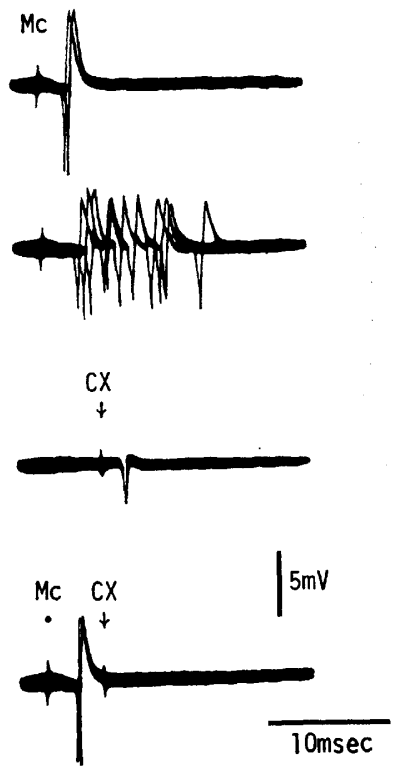

B
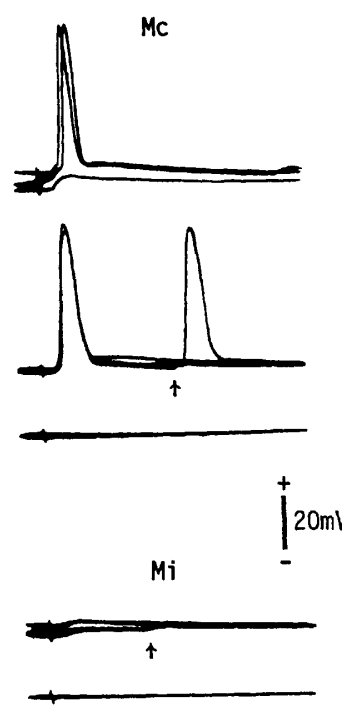

Fig. 4. A: responses of two thalamo-cortical projection neurones to stimulation of the contralateral fastigial (medial) nucleus (Mc) and the medial precruciate cortex (CX). Responses in the 1st and 2nd rows were produced by stimulation at threshold and suprathreshold intensities, respectively. In records of the 4th row, stimulation of the cerebral cortex (downward arrows) was preceded by fastigial stimulation (spot). Upward deflexion indicates negativity. B: responses to stimulation of the contralateral (Mc) and ipsilateral (Mi) fastigial nucleus recorded intracellularly from a neurone in the medial VL nucleus. Responses at longer latencies are marked by upward arrows. Traces in the 3rd and 5th rows show just-extracellular records. Voltage calibration of $5 \mathrm{mV}$ and $20 \mathrm{mV}$ apply to records in A and B, respectively. Time scale of $10 \mathrm{msec}$ for all records. In each frame 2-3 sweeps are superimposed.

response in a given neurone. Intracellular recordings from neurones in the medial VL as well as VM nuclei revealed EPSPs elicited with a latency of 0.7-2.2 msec in response to stimulation of the fastigial nucleus as exemplified in Fig. 4B. In contrast to the reported findings in chloralose-anesthetized cats (BAVA et al., 1979), EPSPs were followed by IPSPs only in a small number of neurones (in 2 out of 12 neurones). As reported previously (MATSUdA and NAKAMURA, 1982), EPSPs with longer latencies were occasionally evoked in addition to the short-latency EPSP (Fig. 4B, upward arrows).

\section{Effects of stimulation of the midbrain reticular formation on thalamic neurones}

Responses of thalamic neurones to fastigial stimulation were modified by conditioning stimuli applied to the midbrain reticular formation as revealed by a 


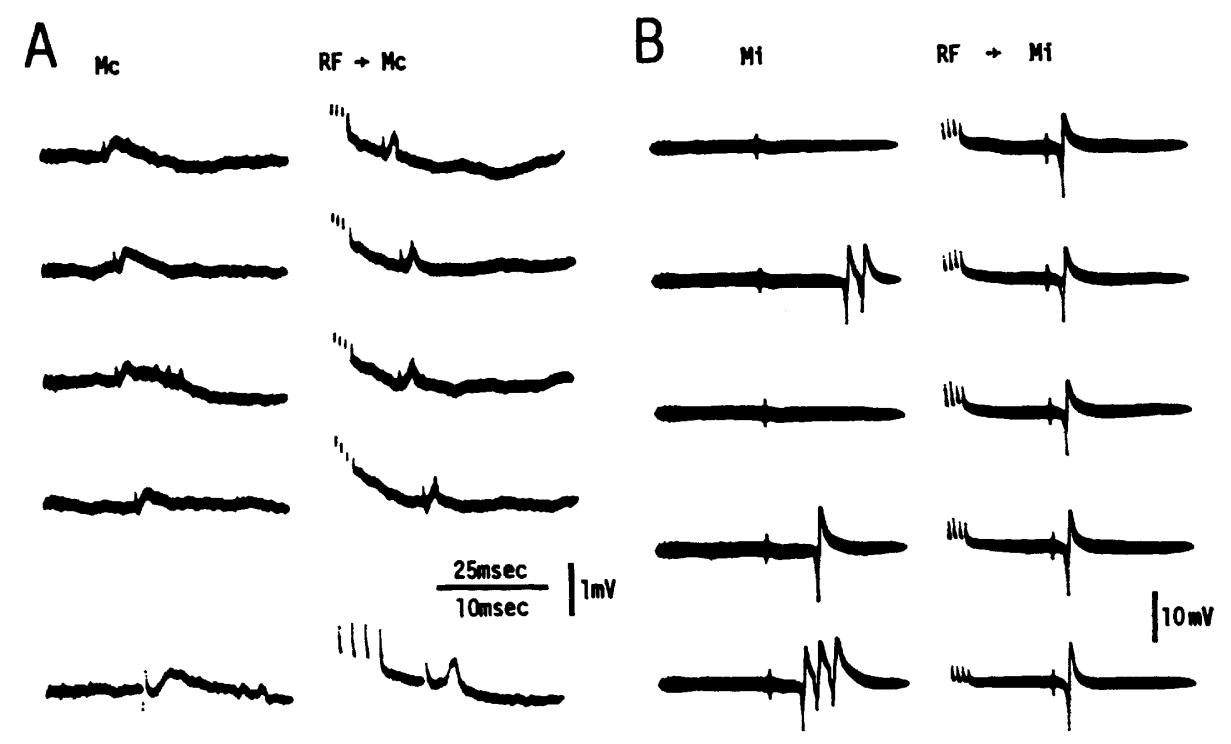

Fig. 5. Effects of conditioning train stimuli applied to the midbrain reticular formation (RF) on the focal potentials (A) and on the unitary responses (B) recorded in the medial VL nucleus. Responses were produced by stimulation of the contralateral (Mc) and ipsilateral (Mi) fastigial nucleus in A and B, respectively. The intensity of fastigial stimulation in B was straddling threshold for unconditioned responses (left column). Control and conditioned responses are presented in pairs in each row. Negativity is indicated by upward deflexion. Voltage calibration of 1 and $10 \mathrm{mV}$ apply to records in $A$ and B, respectively. Sweep calibration of $10 \mathrm{msec}$ apply to the lowermost records in A, that of $25 \mathrm{msec}$ to all others.

change in focal potentials. Stimulation of the fastigial nucleus induced focal mass-potentials in a certain part of the thalamus (ANGAUT et al., 1968). They consisted of a negative wave with a peak at about $2 \mathrm{msec}$ after the stimulus application, and unitary responses were often superposed on the wave (Fig. 5A, 1 st column). These focal potentials should be a reflexion of EPSPs and accompanying spike potentials generated in a population of thalamic neurones responding to fastigial stimulation. The focal mass-responses were changed in shape when conditioning train stimuli were applied to the mesencephalic reticular formation so as to induce a temporary arousal pattern in the electrocorticogram (Fig. $5 \mathrm{~A}, 2$ nd column). The negative peak increased in amplitude while the total duration of the responses was shortened. The effects of stimulation of the reticular formation were also revealed by modifications in unitary responses of thalamic neurones to fastigial stimulation. In the left column of Fig. 5B, the intensity of stimuli applied to the ipsilateral fastigial nucleus was straddling threshold for orthodromic responses in a thalamic neurone. The responses, when evoked, were single or multiple spikes with variable latencies. When a train-pulse stim- 
ulation of the mesencephalic reticular formation was preceded, the thalamic neurone responded to fastigial stimulation with a single spike at a shorter latency (Fig. 5B, right column). Also noted was the enhanced probability of spike generation after combined stimulation of the reticular formation and the fastigial nucleus.

\section{DISCUSSION}

The results in the present study showed that stimulation of the fastigial nucleus could induce cortical responses in the cat under barbiturate anesthesia. The responses were, however, generally small in amplitude. Furthermore, they were not produced in all animals studied. We considered that barbiturate anesthesia would have a tendency to suppress the responses owing, at least, to the interference of transmission in the thalamus as discussed below. In this study, responses to fastigial stimulation, when evoked, were rather confined to the medial part of the precruciate cortex. This distribution of the responses was more restricted than that observed in chloralose-anesthetized cats (RISPAL-PADEL et al., 1971; Rispal-Padel and Latreille, 1974). As argued previously (Dubner and Rutledge, 1964; Feldberg et al., 1957), chloralose seems to facilitate the appearance and to expand the distribution of evoked responses.

The responsive loci of the cortex shown in the present study should be involved mainly in area $6 \mathrm{a} \beta$ according to the cytoarchitectonic subdivision of the cruciate cortex proposed by HASSLER and MuHS-CLEMENT (1964). The responses to fastigial stimulation thus differed in their distribution from those induced by stimulation of the interpositus and dentate nuclei which were largest in magnitude in the lateral part of the contralateral cruciate cortex (SASAKI et al., 1972, 1973). However, laminar recordings of the responses revealed that responses to stimulation of the fastigial nucleus were fundamentally equivalent to those evoked by interpositus and dentate stimulation with respect to their depth profiles of potential distribution, i.e., they were all conveyed by thalamo-cortical projection fibres terminating mainly in the deeper layers of the cortex ("deep thalamo-cortical responses") (SASAKI et al., 1970; SASAKI and Prelević, 1972).

Relay cells for the responses were localized in the medial portion of the VL nucleus and in the VM nucleus of the thalamus. This finding is consistent with the anatomical observation that ascending fibres from the fastigial nucleus terminate bilaterally in these regions of the thalamus (ANGAUT and BowSHER, 1970; NAKANO et al., 1980; SUGIMOTO et al., 1981) and also with the report that thalamocortical projection fibres originating from these thalamic areas terminate in the medial precruciate cortex and the rostromedial portion of the ventral bank of the cruciate sulcus (NAKANo et al., 1978; Strick, 1973; Vedovato, 1978). The observed tendency of thalamic neurones to repetitive spike generation would be a feature reflecting the effects of anesthesia, since cerebellar stimulation usually evokes a single spike with short latencies in the thalamus of the waking unanesthetized cat (FILLION et al., 1971; STERIADE et al., 1971). To the repetitive 
activation of thalamic neurones might be relevant the occurrence of EPSPs with longer latencies after stimulation of the fastigial nucleus (MATSUDA and NAKAMURA, 1982). Also the presumed hyperpolarization of thalamic neurones which might ensue from reduced synaptic bombardments under the influence of anesthesia would be a contributing factor, and this should also lead to a decrease in excitability of thalamic neurones as suggested by the frequent failure of antidromic spikes to invade the cell soma. Stimuli applied to the midbrain reticular formation apparently counteracted the depression of excitability of thalamic neurones, facilitating their activation after stimulation of the fastigial nucleus as shown by the modification of focal potentials and unit firing pattern in the thalamus. Thus the effect of reticular stimulation on the fastigio-thalamic transmission seemed to be similar to that observed in the cerebello-thalamic transmission conveying the output of the interpositus and dentate nuclei to the frontal motor cortex (YASUDA and Shimono, 1978). The observed responses of thalamic neurones suggest that, under pentobarbital anesthesia, fastigial stimulation would not be effective in producing a synchronous activation of thalamic relay cells at a short latency. The inconstancy of cortical responses to fastigial stimulation may at least partly be ascribed to the depressed transmission along the fastigio-thalamic paths which should not be so massive in the cat as the projections from the interpositus and dentate nuclei.

We wish to express our thanks to Prof. K. Sasaki for the critical review of the manuscript.

\section{REFERENCES}

ANGAUt, P. and Bowsher, D. (1970) Ascending projection of the medial cerebellar (fastigial) nucleus: An experimental study in the cat. Brain Res., 24: 49-68.

Angaut, P., Guilbaud, G., and Reymond, M. C. (1968) An electrophysiological study of the cerebellar projections to the nucleus ventralis lateralis of thalamus in the cat. I. Nuclei fastigii et interpositus. J. Comp. Neurol., 134: 9-20.

Bava, A., Cicirata, F., Licciardello, S., Volsi, G. L., and Pantó, M. R. (1979) Fastigial nuclei projection on the ventralis lateralis (VL) thalamic nucleus neurons. Brain Res., 168: 169-175.

Cohen, K., Chambers, W. W., and Sprague, J. M. (1958) Experimental study of the efferent projections from the cerebellar nuclei to the brainstem of the cat. J. Comp. Neurol., 109: 233-259.

Dubner, R. and Rutledge, L. T. (1964) Recording and analysis of converging input upon neurons in cat association cortex. J. Neurophysiol., 27: 620-634.

Feldberg, W., Malcolm, J. L., and Darian Smith, I. (1957) Effect of tubocurarine on the electrical activity of the cat's brain under chloralose. J. Physiol. (Lond.), 138: 178-201.

Fillion, M., Lamarre, Y., and Cordeau, J. P. (1971) Neuronal discharges of the ventrolateral nucleus of the thalamus during sleep and wakefulness in the cat. II. Evoked activity. Exp. Brain Res., 12: 499-508.

Hassler, R. and Muhs-Clement, K. (1964) Architektonischer Aufbau des sensomotorischen und parietalen Cortex der Katze. J. Hirnforsch., 6: 377-420.

JANSEN, J. and JANSEN, J., Jr. (1955) On the efferent fibers of the cerebellar nuclei in the cat.

Vol. 33, No. 2, 1983 
J. Comp. Neurol., 102: 607-632.

Matsuda, Y. and NaKamura, M. (1982) Mode of activation of thalamic neurons by stimulation of the cerebellar fastigial nuclei in the cat. Brain Res., 241: 370-373.

Nakano, K., Takimoto, T., Kayahara, T., Matsuba, H., and Takeuchi, Y. (1978) Horseradish peroxidase labeling of thalamic neurons projecting to the area $6 \mathrm{a} \delta$ and adjacent areas in the cat cerebral cortex. Mie Med. J., 27: 119-135.

Nakano, K., Takimoto, T., Kayahara, T., Takeuchi, Y., and Kobayashi, Y. (1980) Distribution of cerebellothalamic neurons projecting to the ventral nuclei of the thalamus: An HRP study in the cat. J. Comp. Neurol., 194: 427-439.

PaInTaL, A. S. (1959) Intramuscular propagation of sensory impulses. J. Physiol. (Lond.), 148: $240-251$.

RISPAL-PADEL, L. and LATReiLle, J. (1974) The organization of projections from the cerebellar nuclei to the contralateral motor cortex in the cat. Exp. Brain Res., 19: 36-60.

Rispal-Padel, L., Latreille, J., and Venuxem, P. (1971) Répartition sur le cortex moteur des projections des différents noyaux cérébelleux chez le Chat. C. R. Seances Acad. Sci., 272: 451-454.

SaSaki, K., KaWaguchi, S., Matsuda, Y., and Mizuno, N. (1972) Electrophysiological studies on cerebello-cerebral projections in the cat. Exp. Brain Res., 16: 75-88.

Sasaki, K., Matsuda, Y., and Mizuno, N. (1973) Distribution of cerebellar induced responses in the cerebral cortex. Exp. Neurol., 39: 342-354.

SASAKI, K. and Prelević, S. (1972) Excitatory and inhibitory influences of thalamic stimulation on pyramidal tract neurons. Exp. Neurol., 36: 319-335.

Sasaki, K., Staunton, H. P., and Dieckmann, G. (1970) Characteristic features of augmenting and recruiting responses in the cerebral cortex. Exp. Neurol., 26: 369-392.

Steriade, M., Apostol, V., and OAKson, G. (1971) Control of unitary activities in cerebellothalamic pathway during wakefulness and synchronized sleep. J. Neurophysiol., 34: 389413.

StRICK, P. L. (1973) Light microscopic analysis of the cortical projection of the thalamic ventrolateral nucleus in the cat. Brain Res., 55: 1-24.

Sugimoto, T., Mizuno, N., and IтоH, K. (1981) An autoradiographic study on the terminal distribution of cerebellothalamic fibers in the cat. Brain Res., 215: 29-47.

Thomas, D. M., Kaufmann, R. P., Sprague, J. M., and Chambers, W. W. (1956) Experimental studies of the vermal cerebellar projections in the brain stem of the cat (fastigiobulbar tract). J. Anat., 90: 371-385.

Vedovato, M. (1978) Identification of afferent connections to cortical area $6 \mathrm{a} \beta$ of the cat by means of retrograde horseradish peroxidase transport. Neurosci. Lett., 9: 303-310.

YasudA, T. and Shimono, T. (1978) Electrophysiological studies of two types of thalamocortical neurones and their responses to stimulation of mesencephalic reticular formation. Jpn. J. Physiol., 28: 569-581. 